\title{
EL MATERIAL ANTIAÉREO EN EL CONTEXTO DEL EMPLEO CONTRA LAS NUEVAS AMENAZAS EN ECUADOR
}

\author{
Mayor de Artillería Diego René Naranjo Loyola ${ }^{1}$
}

\begin{abstract}
Resumen
Este artículo busca definir el rol del material antiaéreo que dispone la Fuerza Terrestre ecuatoriana frente a las nuevas amenazas asimétricas y multidimensionales. Se trata de aprovechar sus potencialidades de observación, vigilancia, prevención y acción para el fortalecimiento de las operaciones militares relacionadas al ámbito interno, enfocando su análisis a la presencia de amenazas no convencionales, principalmente en la zona litoral ecuatoriana y en la frontera norte con Colombia. Además, este trabajo se enmarca en el Proceso de Transformación del Ejército Ecuatoriano bajo la línea de transformación de "Doctrina", proceso que busca adecuar la institución para enfrentar los nuevos paradigmas con una visión al año 2033; en virtud de lo cual esta investigación plantea una integración doctrinaria de los sistemas operativos del campo de batalla para facilitar su interoperabilidad en la planificación y ejecución de la misión fundamental de Fuerzas Armadas y las misiones complementarias. Con esta adaptación se logrará sincronizar el empleo oportuno de los soldados y de los medios, en tiempo y en espacio, facilitando la integración, coordinación, preparación y ejecución de las operaciones militares en el nivel estratégico, operacional y táctico.
\end{abstract}

Palabras clave: Amenazas asimétricas, sistemas operativos del campo de batalla, material antiaéreo, líneas de transformación y doctrina.

\begin{abstract}
This article seeks to define the role of the anti-aircraft material available to the Army in the face of the new hybrid and multidimensional threats that show their influence in Ecuador, capitalizing its potential for observation, surveillance, prevention and action, for the strengthening of military operations related to the internal environment, focusing its analysis on the presence of conventional threats in the Ecuadorian Coast and in the northern border with Colombia. In addition, this work is framed within the Transformation Process of the Ecuadorian Army, under the "Doctrine" transformation line, a process that seeks to rebuild the institution to face the new paradigms with a vision to the year 2033; Therefore, this research proposes a doctrinal integration of the operational systems of the battlefield to facilitate their interoperability in the planning and execution of the fundamental mission of the Armed Forces and complementary missions. With this adaptation we will allow synchronizing the timely use of soldiers and means, in time and space, facilitating the integration, coordination, preparation and execution of military operations at the strategic, operational and tactical level.
\end{abstract}

Keywords: Asymmetric threats, battlefield operational systems, anti-aircraft material, transformation lines and doctrine.

\footnotetext{
${ }^{1}$ sdrnaranjo99@gmail.com

ACADEMIA DE GUERRA DEL EJÉRCITO ECUATORIANO
} 


\section{Introducción}

$\mathrm{N}$ umerosas son las operaciones militares relacionadas la defensa de la soberanía e integridad territorial, destacando los principios de prevención, disuasión y defensa para alcanzar el éxito de las mismas; sin embargo, en la actualidad se presentan amenazas no tradicionales que se estructuran de diferente manera a un enemigo convencional, que obligan a las Fuerzas Armadas a buscar una articulación integral de los sistemas operativos del campo de batalla con los entes estatales encargados de la seguridad interna de la nación, para hacer frente a estos nuevos actores que buscan propiciar su operación en el Ecuador.

Este trabajo de investigación se contextualiza en el proceso de transformación que está implementando el Ejército Ecuatoriano desde el año 2020 y que se sustenta en 10 líneas de transformación que abarcan: la cultura organizacional, organización, entrenamiento, educación, desarrollo tecnológico, doctrina, gestión humana, marco legal, sostenimiento institucional; y despliegue e infraestructura, con una visión al 2033 de llegar a ser un e jército multimisión, polivalente y multipropósito. Dicho esto, se consideró para este estudio la línea de transformación "Doctrina", que enmarca el empleo del material antiaéreo en apoyo a las operaciones, esto permitirá delinear los roles de funcionamiento de manera adecuada, eficaz y eficiente de la capacidad antiaérea que dispone la Fuerza Terrestre, con base en sus características técnicas, su funcionamiento y forma de empleo, permitiendo que se incursione de lleno en la lucha contra las amenazas no convencionales derivadas del crimen organizado como el narcotráfico o que emplean formas de guerra asimétricas como los grupos ilegales armados, que ejercen influencia en ciertos escenarios del Ecuador.

Actualmente, las operaciones militares responden al cumplimiento de la defensa e integridad territorial y a las misiones complementarias plasmadas en la política de defensa, con una funcionalidad de los sistemas operativos del campo de batalla, criterio acertado para la planificación y ejecución de las operaciones en un escenario de un conflicto armado con otro Estado, en el cual cada sistema coadyuva al cumplimiento de la misión; no obstante, en el caso que se investiga la capacidad antiaérea que forma parte del sistema operativo de apoyo de fuegos, se enfoca en la neutralización y destrucción de los vectores aéreos, propósito fundamental de su empleo, pero que en las operaciones de ámbito interno se ha enrumbado exclusivamente para la vigilancia del espacio aéreo responsabilidad de la Fuerza Aérea Ecuatoriana. Bajo este contexto, nace la siguiente hipótesis: el material de artillería antiaérea del Ejército está siendo utilizando adecuadamente para hacer frente a las nuevas amenazas como parte de la sincronización de los sistemas operativos del campo de batalla.

Para profundizar este análisis es preciso mencionar, que aplicaremos un método de investigación cualitativo, que permite evaluar e interpretar la información que se dispone sobre dos elementos claves en este estudio; el primero, la presencia de nuevas amenazas en el Ecuador; y el segundo, el empleo del material antiaéreo enmarcado en la línea de trasformación de doctrina, en el cual se abordan algunos puntos relacionados a la parte técnica, características y fortalezas en beneficio de las operaciones militares. Dicho esto, este trabajo se divide en cuatro subtemas: iniciando con un marco legal y doctrinario en el cual se destaca las principales normas legales que respaldan el accionar militar, para alinear los criterios doctrinarios del material de artillería antiaérea a la línea de transformación Doctrina, posteriormente, se aborda la presencia de las nuevas amenazas y su forma de operar en ciertos escenarios del Ecuador en los cuales han logrado influencia estos actores, después se analiza si el Sistema Antiaéreo Oerlikon es utilizado en las operaciones de apoyo en la lucha contra el narcotráfico, y con base a esto se plantea un esquema de empleo, dejando para el análisis la propuesta de una "Ley de Derribo", soporte fundamental para el empleo de la capacidad antiaérea del Ejército y aérea de la Fuerza Aérea Ecuatoriana. Finalmente, damos a conocer el uso de las ametralladoras antiaéreas con fines de protección antiaérea a los sectores estratégicos, al personal, material y equipo que se emplea en las operaciones militares en el ámbito interno.

\section{Marco legal y doctrinario contextualizado en la línea de transformación "Doctrina" a. La Constitución de la República del Ecuador}

Art. 158.- Las Fuerzas Armadas y la Policía Nacional son instituciones de protección de los derechos, libertades y garantías de los ciudadanos. Las Fuerzas Armadas tienen como misión fundamental la defensa de la soberanía y la integridad territorial.

\section{b. Ley Orgánica de Defensa Nacional}

Art. 15.- El Comando Conjunto de las Fuerzas Armadas es el máximo órgano de planificación, preparación y conducción estratégica de las operaciones militares y de asesoramiento sobre las políticas militares, de guerra y defensa nacional.

Art. 16.- Las principales atribuciones y deberes del Comando Conjunto de las Fuerzas Armadas, entre otras: planificar el empleo de las Fuerzas Armadas, para contribuir al mantenimiento de la seguridad nacional.

Art. 21.- Son órganos operativos del Comando Conjunto de las Fuerzas Armadas, las Fuerzas Terrestre, Naval y Aérea y los medios operativos propios.

Art. 26.- En cumplimiento del mandato constitucional, cada una de las Ramas de las Fuerzas Armadas deben desarrollar el poder militar para la consecución de los objetivos institucionales, que garanticen la defensa, contribuyan con la seguridad y desarrollo de la Nación, a fin de alcanzar los objetivos derivados de la planificación estratégica militar.

\section{c. Ley de Seguridad Pública del Estado}

Art. 11.- De los órganos ejecutores.- Los órganos ejecutores del Sistema de Seguridad Pública y del 
Estado estarán a cargo de las acciones de defensa, orden público, prevención y gestión de riesgos, conforme lo siguiente: a) De la defensa: Ministerios de Defensa, Relaciones Exteriores y Fuerzas Armadas.La defensa de la soberanía del Estado y la integridad territorial tendrá como entes rectores al Ministerio de Defensa y al de Relaciones Exteriores en los ámbitos de su responsabilidad y competencia. Corresponde a las Fuerzas Armadas su ejecución para cumplir con su misión fundamental de defensa de la soberanía e integridad territorial.

\section{d. Política de la Defensa Nacional 2018}

Define la política del Estado ecuatoriano e incorpora la conceptualización de los riesgos y amenazas que existen en nuestro país y que podrían ser eliminadas o reducidas mediante la ejecución de operaciones militares por parte del Comando Conjunto.

Derivado de esta política, la Fuerza Terrestre tiene como misión desarrollar el poder militar terrestre, preparando, entrenando y equipando al personal militar, mejorando su capacidad operativa de forma permanente y en todo el territorio nacional, para alcanzar los objetivos derivados de la planificación estratégica militar, a fin de coadyuvar en forma conjunta a la defensa de la soberanía e integridad territorial, contribuir en el ámbito interno y en el desarrollo de la Nación (Ministerio de Defensa Nacional, 2018, pág. 97).

\section{e. Plan Estratégico de Seguridad Integral Fronteriza 2018 (Frontera Norte)}

El Sistema de Seguridad Pública y del Estado persigue alcanzar una respuesta integral de las instituciones del Estado en beneficio de todos los habitantes del Ecuador, garantizando el orden público, la convivencia, la paz, en el marco de sus derechos y deberes como personas naturales y jurídicas, comunidades, pueblos, nacionalidades y colectivos, asegurando la defensa nacional y previniendo los riesgos y amenazas de todo orden.

f. Plan Específico de la Defensa Nacional 2019-2030

El Estado ecuatoriano, a través del Ministerio de Defensa Nacional, como organismo rector emite políticas para la defensa y administración de las Fuerzas Armadas y organismos adscritos a fin de garantizar la soberanía nacional e integridad territorial, así como apoyar con su contingente a la seguridad interna y al desarrollo nacional, preservando la seguridad, derechos y garantías de los ciudadanos determinados en la Constitución de la República del Ecuador y demás instrumentos legales.

Las misiones de las Fuerzas Armadas se ejecutan a través del espectro de las operaciones militares, que van desde tiempo de paz, pasando por periodos de crisis hasta la guerra, las mismas que son concebidas en la Política de Defensa Nacional promulgada en el año 2018 y que se detallan en el siguiente esquema:

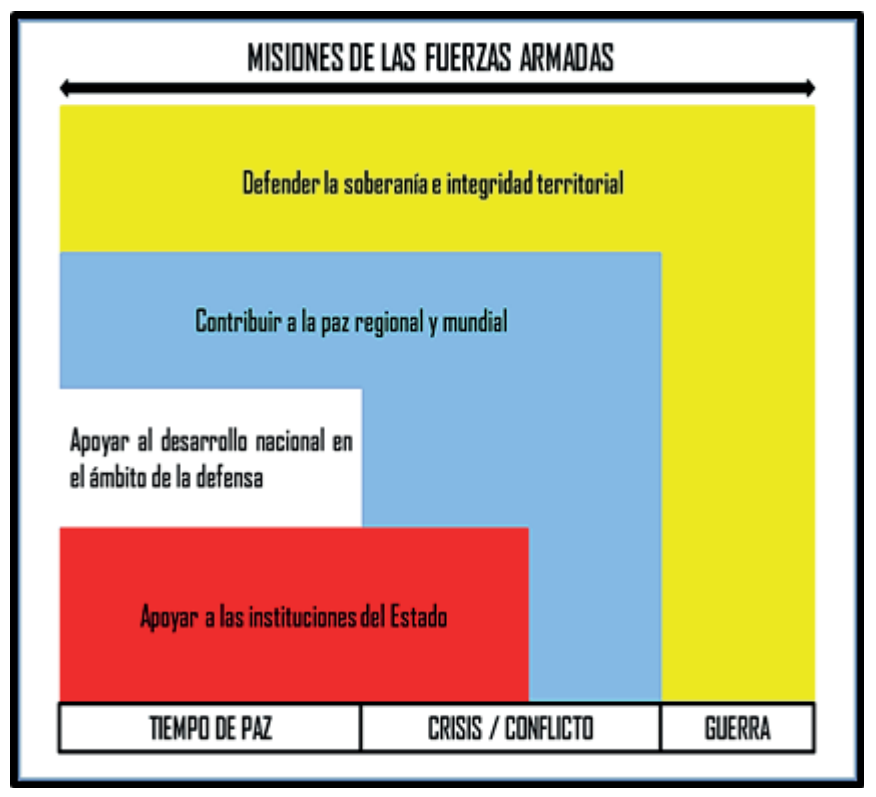

Figura 1. Misiones fundamental y complementarias de las Fuerzas Armadas establecidas en la Política de Defensa Nacional

El Comando Conjunto de las Fuerzas Armadas para el cumplimiento de la misión fundamental y sus misiones complementarias, divide al territorio nacional en zonas de defensa que responden a un análisis de la presencia de amenazas y riesgos, la comunicación vial entre áreas, el mando y control, la sostenibilidad logística y el apoyo a las instituciones del Estado. Esta división permite el cumplimiento de la planificación militar a través de los Comandos Operacionales (Ministerio de Defensa Nacional, 2018, págs. 75-76).

Al momento existen 5 Comandos Operacionales: Norte, Sur, Central, Marítimo y Aéreo, distribuidos sobre la base de los objetivos asignados por el Comando 
Conjunto de las Fuerzas Armadas en el plan de empleo de las Fuerzas Armadas en el ámbito interno, los Comandos Operacionales desarrollan su proceso de planificación en el nivel correspondiente, generando los respectivos planes para el empleo en su respectiva jurisdicción (Comando Conjunto de las Fuerzas Armadas, 2020).

El Ministerio de Defensa Nacional en su informe de gestión 2019 da a conocer la cantidad de operaciones realizadas por las Fuerzas Armadas a través de los Comandos Operacionales como parte de la seguridad y protección terrestre (Ministerio de Defensa Nacional, 2020):

Tabla 1. Operaciones de control en zonas de frontera

\begin{tabular}{lc} 
OPERACIONES REALIZADAS & CANTIDAD \\
\hline Reconocimiento y vigilancia & 10.491 \\
\hline Patrullajes terrestres & 6.221 \\
Operaciones ribereñas & 711
\end{tabular}

Nota. Se muestra el número de operaciones de seguridad y protección terrestres realizadas en 2019

Las Fuerzas Armadas a través del Comando de Operaciones $\mathrm{N}^{\circ} 5$ “AÉREO” participó en las operaciones de seguridad y protección del espacio aéreo, agregando que las horas de vigilancia únicamente se contabilizan con el empleo de los radares Lanza 3D de largo alcance de la Fuerza Aérea:

Tabla 2. Operaciones de vigilancia y protección del espacio aéreo

\begin{tabular}{l|c}
\multicolumn{1}{l}{ OPERACIONES REALIZADAS } & CANTIDAD \\
\hline Horas de vuelo & 11.642 \\
Horas de vigilancia del espacio & 27.328 \\
aéreo (RADAR) &
\end{tabular}

Nota. Se muestra el número de operaciones de vigilancia y protección del espacio aéreo ecuatoriano realizadas en 2019

La Fuerza Aérea Ecuatoriana que tiene como misión institucional: "desarrollar la capacidad militar aeroespacial, que garantice la defensa e integridad territorial; y apoyar con su contingente al desarrollo nacional y a la seguridad pública y del estado" (Comando Conjunto de las Fuerzas Armadas, 2020, pág. 2), para lo cual realiza la vigilancia del espacio aéreo con tareas de seguimiento y control de aproximadamente 250000 aeronaves que sobrevolaron el espacio aéreo jurisdiccional durante el tiempo de operación de los radares de aproximadamente 02 años, entre las cuales se establecieron 18 vuelos como tráfico no identificado que obligaron al empleo de la fuerza de reacción inmediata y en 09 ocasiones para la identificación visual de las mismas (Tcrn. Montenegro, 2019).
Bajo este marco legal y del balance de las acciones militares ejecutadas en el 2019, el Ejército enrumbado en un proceso de transformación, busca en la doctrina uno de los soportes para su empleo efectivo, incorporando una base teórica sólida y actual que le permitirá desarrollar la doctrina de la institución considerando el escenario actual y futuro en función de los requerimientos institucionales; así como también, de difundir la doctrina desarrollada, que debe ir a la par de los procesos de formación, perfeccionamiento y capacitación que son parte de la educación militar de las Fuerzas Armadas. Estos objetivos están implícitos en el denominado "Tiempo 0" de la línea de transformación de Doctrina, punto de partida que generó un nuevo ciclo en la evolución de la doctrina militar transformacional con un nuevo enfoque en el empleo de tácticas, técnicas y procedimientos acordes con las nuevas amenazas y desafíos (Dirección de Transformación y Desarrollo Militar, 2020).

Esta génesis se plasmó con el lanzamiento de la "Doctrina Equinoccio", en noviembre del año pasado, con la cual se espera un cambio conceptual y la adaptación de los soldados del Ejército hasta el año 2033, a las nuevas capacidades que el mundo global requiere con el aparecimiento de nuevas amenazas. Este cambio doctrinario se sustenta en 6 manuales fundamentales del Ejército, complementados por 10 manuales fundamentales de referencia (El Telégrafo, 2020), cumpliendo de esta manera los plazos de la línea de transformación de doctrina que continuará su desarrollo mediante la socialización por medio del sistema de educación continua de la institución y de los procesos de formación, perfeccionamiento y capacitación militar.

Con la implementación de esta doctrina se busca incorporar la sincronización integral de los sistemas operativos del campo de batalla para sustentar la planificación y ejecución de las operaciones militares, tanto para la defensa externa como para el ámbito interno, de esta manera, se plasmará un empleo diferente y efectivo para combatir a las "nuevas amenazas" que son los actuales desafíos que tiene la institución militar.

En el corto plazo la implementación de la Doctrina Equinoccio obliga a una revisión y actualización de los manuales que abordan la temática de conocimiento, operación y empleo cada uno de los armamentos que dispone el Ejército como parte de la capacidad antiaérea, para adecuarlos a la realidad doctrinaria y al empleo actual dentro de la defensa externa como también del ámbito interno.

\section{Las nuevas amenazas presentes en el Ecuador}

Es fundamental definir el concepto de amenaza; sobre la base, de la afirmación de las Naciones Unidas, como: “...cualquier suceso o proceso que cause muertes en gran escala o una reducción masiva en las oportunidades de vida y que socave el papel del Estado como unidad básica del sistema internacional constituye 
una amenaza a la seguridad internacional" (Ministerio de Defensa Nacional, 2018, pág. 46). Otros autores la definen también como:

El conjunto de capacidades, intenciones y acciones actuales o potenciales, que buscan impedir o interferir el logro exitoso de los objetivos de un Estado-Nación, grupo de Estados o la totalidad del Continente; acciones o situaciones internas y/o externas que atentan en contra los Objetivos Nacionales Permanentes. (Bravo W. y Armas F., 2004, pág. 39).

Otro concepto enfocado al estudio de las amenazas asimétricas la detalla la National Defense University que señala: "son una versión de "pelea sucia" o de "pelea no limpia", la que puede incluir el uso de la sorpresa en toda su dimensión estratégica y operacional y el empleo de las armas de ma $\neg$ nera no prevista o planificada" (Larraín \& Horacio, 2015).

Estas nuevas amenazas tienen una estructura híbrida, la cual consta de elementos regulares, irregulares y criminales que trabajan con toda sinergia por un estado final común, factores que direccionan una futura guerra híbrida, que pondrá a prueba la destreza, preparación y flexibilidad del soldado del futuro para hacer frente a estas amenazas en constante evolución (Mayor Davis, 2013).

De acuerdo con la Política de Defensa Nacional se identifican 3 amenazas potenciales al Estado ecuatoriano: la agresión armada externa ejecutada por las Fuerzas Armadas de otro Estado, los grupos ilegales armados que inciden negativamente en la seguridad y defensa, especialmente en la zona de la frontera norte y finalmente, el crimen organizado asociado con delitos conexos como el tráfico de armas, municiones y explosivos, el narcotráfico, tráficos de personas, tráfico ilícito de inmigrantes y el contrabando de mercaderías, que tienen como propósito lograr el poder económico, político o social (Ministerio de Defensa Nacional, 2018).

Los conceptos y la identificación de las nuevas amenazas nos permiten comprender que la amenaza busca vulnerar la defensa y la seguridad del Estado a través de actividades ilícitas que, directa o indirectamente, afectan a la paz, armonía y tranquilidad de la sociedad, la afección de los sectores estratégicos del Estado y en definitiva, al desarrollo de la nación; por ende, es imprescindible que las fuerzas militares las enfrenten con base en una sinergia de los sistemas operativos.

La influencia de las nuevas amenazas en el Ecuador, direccionan a que este análisis sea delimitado en dos escenarios, el primero a la frontera norte del Ecuador, en razón que desde la firma del Plan Colombia entre los países de Estados Unidos y Colombia en 1999, se estableció una lucha sin descanso en contra de las Fuerzas Armadas Revolucionarias de Colombia (F.A.R.C), organización que fue catalogada por varios países del escenario mundial como un grupo terrorista.
El nivel político del Ecuador nunca la reconoció como tal, lo que hubiera implicado la participación del país en esta lucha, que de acuerdo a la posición del Gobierno Nacional, la concibió como un problema interno del vecino país del norte, cerrando cualquier posibilidad de involucramiento; y daños colaterales a la defensa y seguridad del Estado. Sin embargo, las operaciones militares de las Fuerzas Armadas de Colombia ejecutadas por varios años en la frontera, trajeron grandes y graves problemas al Ecuador, como el incremento de la delincuencia, contrabando, tráfico de armas, munición y explosivos, narcotráfico, inmigración, presencia y desplazamiento de grupos ilegales armados en el límite fronterizo, en bases clandestinas destinadas al reabastecimiento, descanso y reorganización de sus fuerzas, para posteriormente continuar en sus acciones ilícitas en el lado colombiano. A estos acontecimientos se suman, la Operación Fénix ejecutada el 01 de marzo de 2008, que consistió en una incursión con helicópteros y personal militar colombiano al territorio ecuatoriano, a una zona selvática del Ecuador denominada "Angostura", en la provincia de Sucumbíos; producto del bombardeo murió "Raúl Reyes" y 17 guerrilleros más, golpe duro a las FARC y fundamental para acabar con el grupo armado ilegal (Pastrana \& Trujillo, 2011).

Otro de los eventos perpetrados en contra de la defensa y seguridad del Estado ecuatoriano, se dio en el sector de Mataje y San Lorenzo durante el año 2018, que culminaron con la muerte de militares, periodistas y ciudadanos ecuatorianos en manos de la influencia de los grupos disidentes de la ex guerrilla de las FARC, miembros que se desintegraron de un proceso de paz que se realizó en Colombia entre el Estado y las FARC y del Ejército de Liberación Nacional (E.L.N), que han hecho presencia en las provincias de Esmeraldas, Carchi y Sucumbíos.

Los Grupos Ilegales Armados y sus disidencias, se encuentran localizados a lo largo del cordón fronterizo al norte del Ecuador, incursionando en el fácil acceso a la tecnología para adquirir RPAS (Remotely Piloted Aircraft System), por sus siglas en inglés o también conocidos como drones, objetos que les han permitido visualizar en tiempo real las actividades militares que ejecuta el Ejército Ecuatoriano como parte de las operaciones de protección de fronteras y de los destacamentos militares que se localizan cerca a límite político internacional. El 21 de agosto de 2020 en horas de la madrugada se observaron a tres drones sobrevolando el puente internacional Mataje y el destacamento militar ubicado a tres kilómetros de la parroquia del mismo nombre, cuyo itinerario consistía en el sobrevuelo del puente internacional y el reparto militar en el lado ecuatoriano, para posteriormente retornar a territorio colombiano (Campaña, 2020, pág. 2). No es la primera vez que suceden estos hechos, ya en el año 2018 varias patrullas ecuatorianas divisaron drones que sobrevolaban el sector fronterizo y que precisamente venían desde lado colombiano, presumiblemente con la tarea de localizar 
al personal militar y determinar sus actividades, para acto seguido continuar sus operaciones ilícitas en sectores sin resguardo legal.

Por lo antes descrito, no es difícil pensar que en el ámbito regional se utilicen estos artefactos como armas en contra de las fuerzas legales, encuadrados en el empleo de drones comerciales como vectores terroristas que señala el autor José Martín Delgado del Instituto Español de Estudios Estratégicos, quien manifiesta: que un aproximado de 17 atentados terroristas aproximadamente con drones se han ejecutado en el mundo, y en su gran mayoría con resultados exitosos en contra de bienes estratégicos y las fuerzas del orden; sin embargo otros, a pesar que no han tenido éxito total, han causado daños colaterales significativos. Los principales grupos terroristas que han utilizado estos artificios aéreos de control remoto, son los que ejercen influencia en Medio Oriente como: Hezbolá, Hamás, Partido Islámico de Turkestán, Grupo Yijadista vinculado a Al Qaeda, Ejército de la Conquista (Jays Al-Fath) y Estado Islámico; inclusive las Fuerzas Armadas Revolucionarias de Colombia durante el 2002 planificaron un ataque con estas características, pero felizmente sin éxito (Delgado, 2018).

Por otro lado, el crimen organizado y sus delitos conexos como el narcotráfico han hecho del territorio ecuatoriano un paso ideal para el trasporte de drogas, a pesar que el Ecuador no es considerado un productor de este tipo de sustancias sujetas a fiscalización a gran escala; no así sus vecinos de Perú y Colombia. En su más reciente informe, la oficina de la Organización de las Naciones Unidas (ONU) contra la droga y el delito, señala que Colombia sigue siendo el mayor productor mundial de coca con fines ilícitos (RCN Noticias, 2020).

El Ecuador llama poco la atención en el contexto mundial, ya que no hay carteles de la droga como los que han dominado la criminalidad de países como México y Colombia.

Sin embargo, se lo ha denominado como una de las "superautopistas de la cocaína del mundo", tal cual le gusta al narcotráfico internacional "poco ruido y bajo perfil", pues más de un tercio de la creciente producción de cocaína en Colombia llega actualmente a Ecuador, según fuentes antinarcóticos ecuatorianas. La droga sale de los puertos, las costas, los aeropuertos y pistas clandestinas del país, y de allí se envía a Estados Unidos, Centro América, Europa e incluso Asia y Oceanía (Bargent, 2019).

Las rutas del narcotráfico en Ecuador se derivan principalmente al Pacífico y la Amazonía, la primera ruta es abastecida en su mayor parte por la cocaína que se produce en Nariño, departamento fronterizo que tiene más coca que cualquier otro lugar de Colombia, el modo de actuar es el siguiente: las drogas ingresan a Ecuador, bien sea en pequeñas embarcaciones que navegan por vías fluviales de la selva y convergen en el río Mataje, hasta llegar a Esmeraldas, cruzan el puente internacional o por los pasos clandestinos de la frontera hacia Carchi, los cargamentos son recolectados en puntos de acopio cerca de la frontera y por carretera se acercan a los puntos de despacho.

La ruta amazónica se abastece en su mayor parte de cocaína de Putumayo, el departamento colombiano con el segundo nivel más alto de cultivos de coca después de Nariño, y se adentra a la provincia de Sucumbíos, utilizando las vías fluviales de los ríos San Miguel y Putumayo, donde pequeñas embarcaciones depositan cargas en puntos de acopio ubicados en Puerto Nuevo, Puerto Mestanza y Tarapoa, para posteriormente tomar las principales carreteras del país hacia los puntos de despacho (Bargent, 2019).

Actualmente, la mayor parte de la cocaína que se envía de Ecuador hacia el mercado estadounidense sale de las costas de Esmeraldas, Manabí, Santa Elena y, en menor medida, de Guayas y El Oro, y lo hacen en lanchas a motor, aunque los traficantes también utilizan buques pesqueros, sumergibles y barcos con revestimientos de fibra de vidrio que las autoridades antinarcóticos llaman vehículos de bajo perfil, siendo este el principal método para el transportar cocaína hacia los Estados Unidos, a travesando Centro América y México; sin embargo, el uso de Ecuador como puente aéreo se ha incrementado, debido a los resultados de los controles y la presión que ejercen las autoridades en las rutas marítimas; lo cual ha obligado a los narcotraficantes a utilizar avionetas principalmente las Cessna, las cuales son modificadas para que puedan transportar una mayor cantidad de drogas y combustible para alcanzar su destino, y que incluso pueden reabastecerse en el aire.

Estas avionetas pueden transportar entre 400 y 700 kilos, y en cuestión de seis horas llegar a Costa Rica o Guatemala, donde descargan su contenido, o bien repostan y continúan hacia México. Estos vectores aéreos que cumplen misiones ilícitas despegan desde diversas pistas clandestinas o improvisadas, pues los narcotraficantes las construyen en zonas aisladas, camufladas o aprovechan pistas ya existentes en propiedades privadas o comerciales, como las utilizadas para el riego de los cultivos en la zona agraria principalmente en el litoral ecuatoriano (Bargent, 2019).

En la Figura 2 de la página siguiente se pueden apreciar las rutas aéreas y fluviales que recorren las drogas por el territorio nacional. 


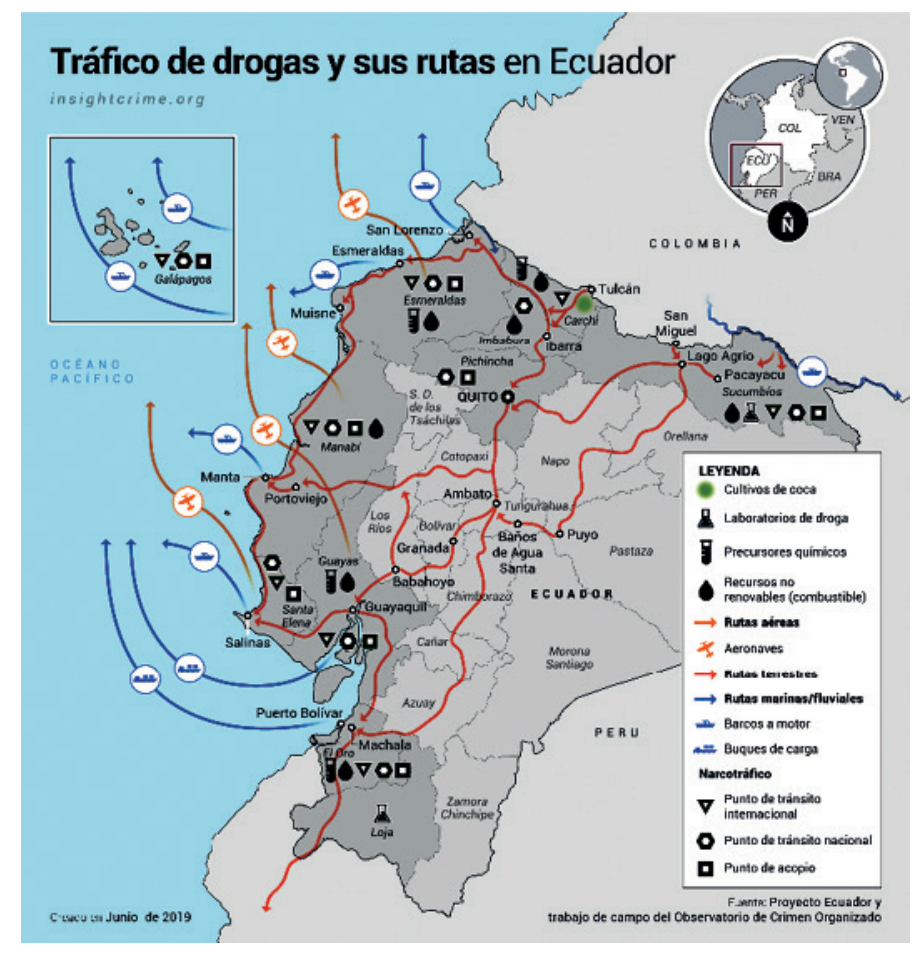

Figura 2. Rutas terrestres, aéreas y fluviales de la droga en el Ecuador

En el año 2019 las autoridades del Ecuador relacionadas al ámbito de la seguridad y defensa señalaron que existen más de 2000 pistas no controladas en el Ecuador y que muchas de ellas son utilizadas por los narcotraficantes, además que cerca de las pistas se han encontrado indicios que sustentan la permanencia de aeronaves en esos sectores, a tal punto que la abandonada Refinería del Pacífico, fue utilizada como pista de aterrizaje en el mes de abril de 2019 (Plan V, 2020).

Asimismo, una investigación policial determinó que hasta el mes de abril de 2019 se habían incautado 20 avionetas relacionadas al narcotráfico en diversos operativos, un $95 \%$ de estas han volado a baja altura para evadir la detección de los radares que dispone la Fuerza Aérea Ecuatoriana, estas denominadas "narco avionetas" son de marca Cessna y pueden volar hasta 1 290 kilómetros de distancia, lo que equivale al trayecto de Ecuador a Costa Rica, aunque las investigaciones indican que salen desde Manabí y van directo a Guatemala, donde se reabastecen de combustible en pistas clandestinas para luego llegar a su destino final, que es México. Estas aeronaves pueden perderse del control radárico en zonas montañosas y logran aterrizar hasta en potreros, caminos vecinales o canchas de fútbol, por lo que son preferidas por su fácil maniobrabilidad; además, que son modificadas para librarlas de peso y aumentar la carga de droga, también llevan en su interior combustible para su reabastecimiento, el cual permite incrementar su tiempo de vuelo (El Diario, 2019).

La permeabilidad del Ecuador es evidente y el narcotráfico ha ganado espacio en el país a tal punto que en el año 2020 la Policía Nacional, con el apoyo de la Armada, incautó un total de 128,4 toneladas de droga, logrando ser la mayor incautación de la última década, según los datos proporcionados por el Ministerio de Gobierno; sin embargo, el panorama regional no es alentador, ya que la producción de droga sigue en aumento, así lo menciona el último estudio de la Organización de las Naciones Unidas para la Droga y el Delito (Ortiz, 2021).

\section{El empleo de los directores de tiro del Sistema Antiaéreo Oerlikon en las operaciones de apoyo militar en la lucha contra el narcotráfico}

Las Fuerzas Armadas, para cumplir la misión fundamental de defender la soberanía e integridad territorial, su organización y empleo, se orientan a contrarrestar las amenazas, con prioridad en las zonas de frontera, mediante un sistema integrado de alerta temprana articulado con el subsistema de inteligencia militar que le permita detectar oportunamente la inminencia de cualquier tipo de agresión, empleando comandos operacionales conformados por unidades de las tres ramas de las Fuerzas Armadas, con capacidad operativa y autonomía logística, mediante la preparación, prevención, disuasión defensiva, defensa y cooperación internacional, a fin de obtener la iniciativa y decisión estratégica, que permita alcanzar el objetivo político de la defensa (Ministerio de Defensa Nacional, 2018).

La Fuerza Terrestre, componente básico de las Fuerzas Armadas, se organiza en proporción adecuada con unidades de combate, unidades de apoyo para el combate y unidades de apoyo de servicio de combate; 
y se articula, según los criterios de funcionalidad y operatividad, en unidades y organismos de distintos tipos, en forma flexible, armónica y polivalente, para hacer frente a sus responsabilidades. Con base en esta organización, el arma de artillería forma parte constitutiva de las armas de apoyo de combate y considera para su empleo los sistemas de campo y antiaéreo, los cuales se materializarán con base en sus funciones específicas de apoyo a la maniobra de las unidades de combate.

En el caso que se analiza, las armas antiaéreas que dispone el Ejército han sido asignadas al Grupo de Artillería Antiaérea N. ${ }^{\circ}$, unidad que se estructura de 5 baterías de tiro antiaéreas, las mismas que se encuentran desplegadas en sectores específicos del territorio nacional y dispone del siguiente material bélico:

Tabla 2. Operaciones de vigilancia y protección del espacio aéreo

\section{ARMAMENTO CANTIDAD CALIBRE}

\begin{tabular}{lcc}
\hline Sistema Oerlikon & 24 & 35 milimetros \\
Misiles IGLA & 220 & 72 milimetros \\
Ametralladoras múltiples & 26 & 12.7 milimetros \\
cal. 0.50 pulg. & & \\
Ametralladoras ZGU-1P & 32 & 14.5 milimetros
\end{tabular}

Nota. Se muestra el material antiaéreo que dispone el Ejército Ecuatoriano

Esta unidad militar dispone de toda la capacidad antiaérea de la Fuerza Terrestre y a la vez forma parte constitutiva de la defensa aérea cuya responsabilidad es de la Fuerza Aérea Ecuatoriana, interrelacionándose con este organismo a través de las Unidades de Defensa Antiaérea (UDAA), que son parte del Sistema Conjunto de Defensa Aérea y que, una vez activada la alarma temprana, pueden proporcionar protección antiaérea de las áreas consideradas sensibles para detectar, enganchar, identificar y destruir incursiones aéreas enemigas a baja altura, todo esto forma parte de su empleo para la defensa externa de la nación; sin embargo, para las operaciones de ámbito interno, no se contempla su empleo, como se puede evidenciar en la Tabla 2 que refleja el número de operaciones de vigilancia y protección del espacio aéreo realizadas en 2019 y que basan esa vigilancia únicamente al uso de aeronaves y radares de la Fuerza Aérea, obviando el empleo de las armas antiaéreas, elemento constitutivo de los sistemas de armas componentes de la defensa aérea.

En el marco de la seguridad y defensa existe la organización de la defensa aérea que la ejecuta el Comando Operacional N. 5 "Aéreo", con un subsistema de vigilancia, que comprende los radares, comunicaciones, personal y procedimientos inherentes a la defensa aérea; un subsistema de armas, compuesto de aviones interceptores y armas antiaéreas; y un subsistema de comando, control, comunicaciones, computación, inteligencia, vigilancia y reconocimiento (C4IVR), encargado del empleo eficaz de los medios a fin de integrar los diferentes elementos del sistema de defensa aérea en una entidad única para asegurar el uso óptimo de los recursos disponibles. En este contexto, como parte del subsistema Armas se dispone del Sistema Antiaéreo de 35 milímetros Oerlikon, que se considera como una unidad de tiro que cuenta con equipos de detección y control de tiro, contra aéreos que vuelan a mediana, baja y muy baja altura, siendo muy útil en la defensa de puntos vitales, con una capacidad de detección teórica a $45 \mathrm{~km}$ y un alcance de neutralización a 4 km. (Fuerza Aérea Ecuatoriana, 2013).

Los directores de tiro (radares) del Sistema Antiaéreo Oerlikon fueron modernizados en el año 2020 en un trabajo conjunto entre el Centro de Investigación de Aplicaciones Militares de la Universidad de Fuerzas Armadas ESPE y el Centro de Mantenimiento de Artillería del Ejército, alcanzando los objetivos propuestos de incrementar y mejorar la capacidad de exploración del sistema radárico de 17 kilómetros de alcance efectivo a 22 kilómetros, y dejando sus subsistemas hidráulico y eléctrico en perfectas condiciones (Comisión técnica de entrega y recepción de los radares, 2020). Este gran avance permitirá en un futuro generar proyectos de mantenimiento de las piezas de tiro de 35 milímetros y sus respectivos grupos electrógenos para recuperar la capacidad operativa total de este sistema antiaéreo.

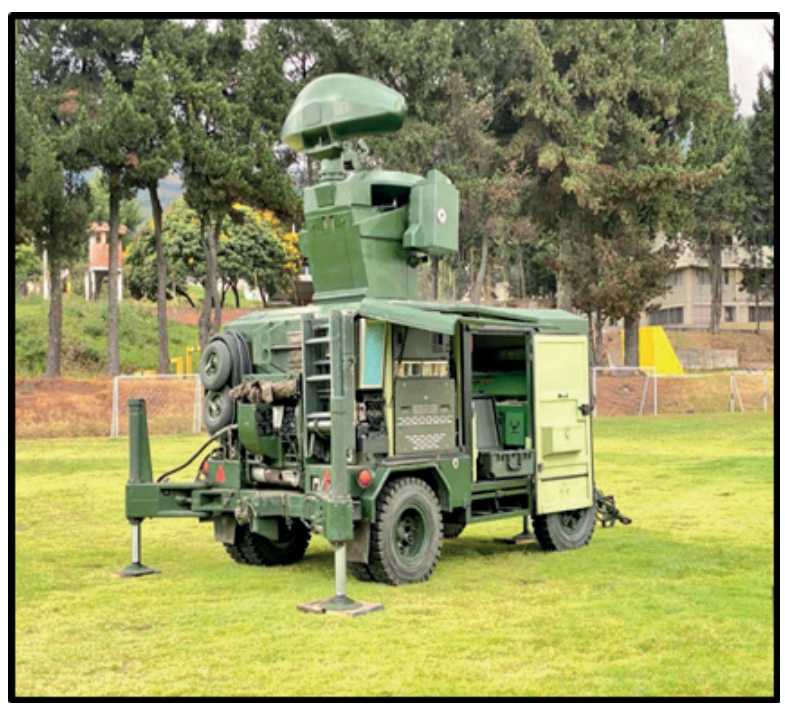

Figura 3. Director Tiro del Sistema Oerlikon modernizado

La modernización de los directores de tiro del Sistema Antiaéreo Oerlikon, pueden complementar el trabajo de detección de avionetas que cumplen actividades ilícitas relacionadas al narcotráfico, integrándose a fortalecer la misión que cumple el Comando de Operaciones Aéreas y Defensa Aérea y responsable de la planificación y ejecución de la defensa aérea de todo el país, tanto en tiempos de paz como de guerra, principalmente direccionando su funcionamiento a cubrir los ángulos 
muertos; entendiéndose a éstos como las áreas que no pueden ser exploradas por los sistemas radáricos Lanza 3D de largo alcance de la Fuerza Aérea, los mismos que proporcionan la altura de vuelo de las aeronaves dentro de su zona de cobertura, el azimut, la velocidad y la distancia de dichos blancos respecto a la posición del radar y justamente por su ubicación en sectores altos para evitar la interferencia del sistema montañoso ecuatoriano están supeditados a la existencia de áreas que no podrán ser exploradas por sus dispositivos, y en esos sectores podrán operar los directores de tiro (radares) del sistema antiaéreo del Ejército para proporcionar la vigilancia y control del espacio aéreo mediante la detección y seguimiento de aeronaves. De esta manera, los radares podrán articularse a una red de alarma temprana que iniciaría su misión con la vigilancia por parte de los sistemas radáricos de la Fuerza Aérea Ecuatoriana y el sistema complementario de los directores de tiro Oerlikon; una vez detectada e identificada la aeronave que no cuenta con la respectiva autorización para sobrevolar el espacio aéreo ecuatoriano, información que es proporcionada por parte de la Dirección General de Aviación Civil, se activará el subsistema armas con la Fuerza de Reacción Inmediata (FRI) conformada por las aeronaves de la Fuerza Aérea que estarán encaminadas a realizar el acompañamiento de la aeronave ilegal hasta su aterrizaje en el aeropuerto o la pista aérea más cercana. Al mismo tiempo de la identificación de la aeronave ilícita; el subsistema de comando, control, comunicaciones y coordinaciones debe dar aviso a los organismos de control estatales, en este caso a las Fuerzas Armadas y Policía Nacional a través del Sistema Integrado de Seguridad ECU-911, para que una vez que la avioneta ilegal aterrice se proceda a la detención de la tripulación con fines investigativos y finalmente la Fiscalía se encargue de iniciar el proceso de investigación correspondiente. Este esquema descrito anteriormente se basa en el criterio de acción unificada "que no es más que la sincronización, coordinación y/o integración con entidades gubernamentales y no gubernamentales con las operaciones militares para alcanzar la unidad de esfuerzo" (Fuerza Terrestre, 2020, pág. 6), que se explica en la siguiente figura:

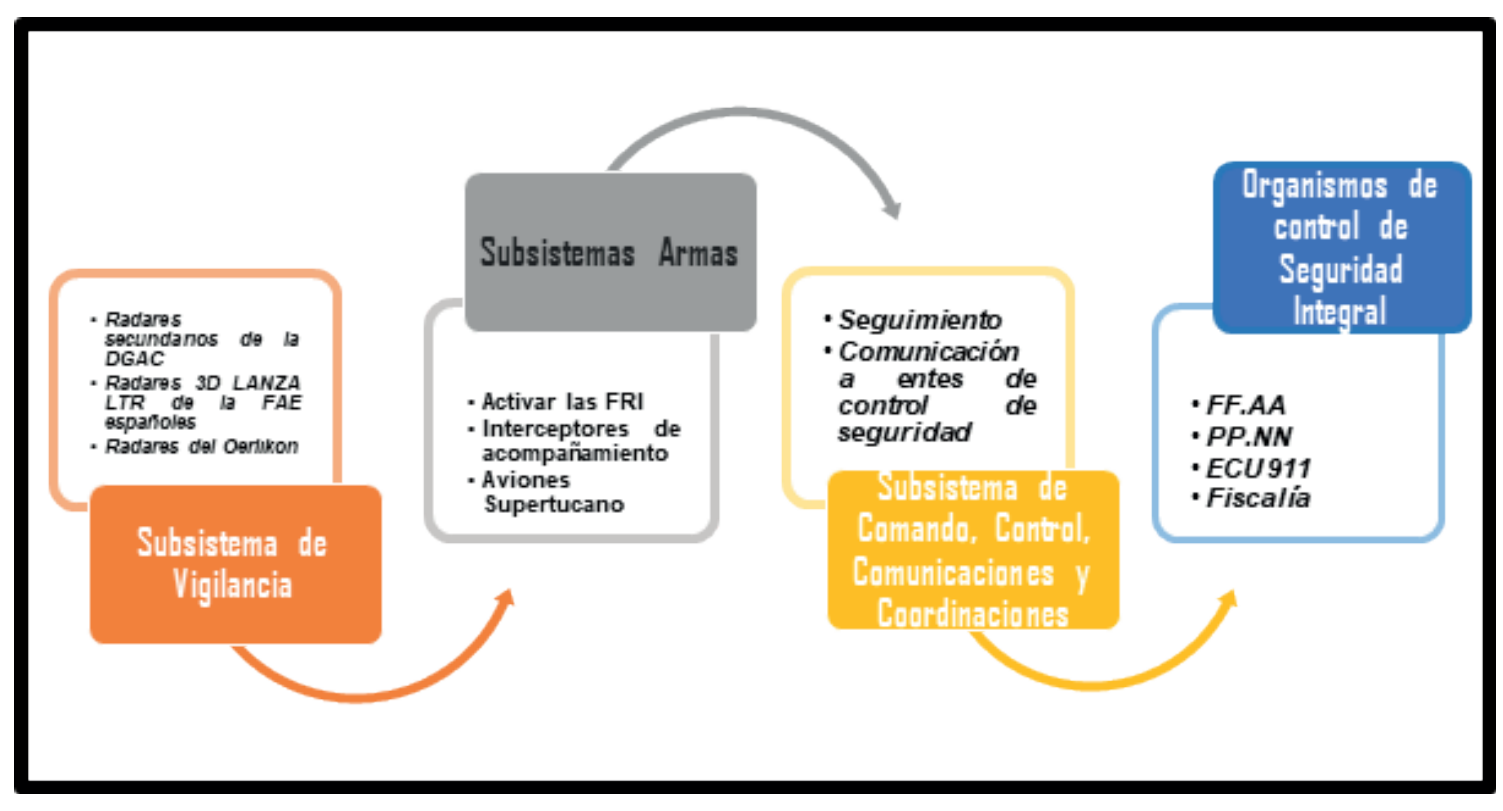

Figura 4. Esquema de empleo de los subsistemas para la defensa aérea en el ámbito interno

Este es el campo de acción que se vislumbra para el material de artillería antiaérea del Ejército, para el apoyo a las operaciones militares relacionadas al ámbito interno como un medio de disuasión, acompañamiento y seguimiento, enmarcándose en la normativa internacional del uso del espacio aéreo que señala: que los Estados en ejercicio de su soberanía, tienen derecho de exigir el aterrizaje de un tráfico no identificado (T.N.I.) en un aeródromo controlado, asimismo puede dar a dicha aeronave toda otra instrucción necesaria para poner fin a este acto de violación; además, la Organización de Aviación Civil Internacional señala referente a la interceptación de aeronaves civiles que: ninguna aeronave civil será objeto de interceptación, y complementa que de ser estrictamente necesario, la interceptación se realizará solo con fines de identificación (Comando Conjunto de las Fuerzas Armadas, 2020); sin embargo, en la búsqueda de un empleo integral y de la propia naturaleza del armamento antiaéreo, cuyo propósito es neutralizar o destruir incursiones aéreas sean enemigas o ilícitas, es fundamental que se cuente con una legislación que permita el derribo de las aeronaves como último recurso, esto fundamentalmente debido a que las aeronaves que cumplen actividades 
ilícitas de narcotráfico, muy difícilmente con el papel disuasivo de acompañamiento que ejecutan las aeronaves de la Fuerza Aérea Ecuatoriana, accederán a aterrizar de forma voluntaria; por lo que surge la necesidad que el Ecuador disponga de una "Ley de Derribo", no solo como una medida de disuasión sino también como evidencia de la lucha del país en contra del crimen organizado transnacional.

Esta propuesta de análisis no es diferente a la realidad de otras naciones en el ámbito regional; en virtud que varios países sudamericanos desde décadas atrás, cuentan en sus legislaciones con esta ley y de los procedimientos que les permiten afrontar amenazas derivadas de los vuelos ilícitos; tal es el caso de Brasil, Argentina, Venezuela, Perú y Colombia (Fuerza Aérea Ecuatoriana, 2013, págs. 9, 10 y 11). Estos países se han preocupado por tener procedimientos claros para enfrentar amenazas derivadas de los vuelos ilícitos relacionados al narcotráfico, que en forma muy general engloban los siguientes aspectos:

a. Reconocimiento visual de la aeronave irregular.

b. Verificación de datos en el centro de control de vuelos.

c. Determinada la irregularidad del vuelo, se intentará tomar contacto radical mediante la frecuencia internacional de emergencia.

d. En caso de no responder a los avisos radiales, se considerará el vuelo sospechoso y se ordenará su aterrizaje mediante señales visuales.

e. Si se mantiene la desobediencia, se habilitará al piloto interceptor a disparar munición trazadora (que es visible en su trayectoria) a modo de advertencia.

f. De persistir la situación, el vuelo será declarado hostil y se permitirá su derribo (Fuerza Aérea Ecuatoriana, 2013, pág. 10).

Así también, Bolivia promulgó en el 2014 la Ley de Seguridad y Defensa del Espacio Aéreo, en la cual se detallan los procedimientos y controles para la vigilancia y la defensa del espacio aéreo boliviano, y también autoriza el derribo de aeronaves no autorizadas o que incumplan con la normativa vigente (Lohmuller, 2014). Otro país que dispone de normativa relacionada al tema, aunque no como una ley expresa, es Chile, país que cuenta con un decreto supremo firmado en diciembre de 2006 por Michelle Bachelet, denominado Reglamento DAR 91 que regula la forma, las circunstancias y en qué casos se puede actuar para la interceptación de aeronaves civiles que representen un peligro y únicamente llegar al derribo como último recurso (La Voz, 2016).

Al no existir esta ley en Ecuador, muy probablemente el accionar del crimen organizado y sus delitos conexos como el narcotráfico fortalecen sus decisiones de continuar operando en el país; por lo que suena paradójico señalar que la defensa del espacio aéreo nacional debe involucrar el ejercicio de la soberanía sobre dicho espacio, para lo cual se debe impedir el funcionamiento de aeronaves cuya finalidad de vuelo sea causar actos hostiles o ilegales, no obstante, sin una ley que norme este accionar, difícilmente se podrá conseguir este cometido.

En la actualidad no existe ninguna propuesta de una Ley de Derribo en la Asamblea Nacional, no obstante es fundamental que las Fuerzas Armadas cuenten con este marco legal para su pleno accionar en el campo de la defensa aérea, logrando así la concepción de la capacidad antiaérea y aérea como multipropósito, respaldado en un cuerpo legal en el cual se estipule exactamente las normas y procedimientos que guíen la interceptación de la aeronave hostil o ilegal, tal cual disponen la mayoría de países de Sudamérica; eso sí, considerando al derribo, como una medida de último recurso.

\section{El empleo de las ametralladoras antiaéreas en apoyo a las operaciones militares en el ámbito interno que se ejecutan en la frontera norte}

Las operaciones militares son particulares, pues la amenaza es asimétrica o híbrida y desde la clandestinidad hace daño; sin duda alguna las fuerzas militares deben estar preparadas, instruidas y equipadas para enfrentas a estos actores no habituales que operan en el interior de nuestras fronteras e inclusive el apoyo a las operaciones militares en el ámbito interno, al igual que en las operaciones convencionales es primordial el apoyo de combate, con ciertas restricciones tácticas y técnicas, por lo que el éxito de las mismas dependen mucho de la planificación (Comando de Educación y Doctrina Militar Terrestre, 2020, pág. 164 y 165).

En referencia a lo antes citado, la defensa aérea contempla en su estructura al subsistema armas, el mismo que se subdivide en dos grupos: aviones interceptores y las armas antiaéreas.

El subsistema de armas antiaéreas tienen como propósito realizar la defensa antiaérea de objetivos estratégicos, centros de gravedad, áreas y puntos sensibles, tropas estacionadas o en movimiento, protegiéndolos contra ataques aéreos y de misiles hostiles, ya sea destruyendo, neutralizando o impidiendo que estos alcancen su objetivo (Fuerza Aérea Ecuatoriana, 2013, pág. 39).

Bajo este contexto, es acertado que el material antiaéreo como parte del sistema de apoyo de fuegos, sea empleado en forma articulada a sus similares de maniobra, inteligencia, mando tipo misión-mando y control, durante la ejecución de las operaciones militares en el ámbito interno y así lograr la protección antiaérea de áreas estratégicas localizadas cerca de la frontera norte del país, y como medida de prevención, disuasión y protección del personal militar que ejecuta operaciones de vigilancia, control y reconocimiento terrestre, más aun considerando la vulnerabilidad de las fuerzas militares cuando se tiene indicios que los grupos ilegales armados que operan en la frontera, utilizan drones para vigilar las actividades militares 
ecuatorianas; además, no se puede descartar que estos medios sean utilizados para atentados terroristas en contra de las fuerzas de seguridad y bienes estratégicos del Estado, como los hechos sucedidos en diversas partes del mundo. En el caso puntual del apoyo a las operaciones en el ámbito interno en Ecuador, el empleo de las unidades de artillería antiaérea debe centrarse en el uso de ametralladoras y cañones antiaéreos, bajo el mismo criterio del uso progresivo de la fuerza expreso en los Principios Básicos sobre el Empleo de la Fuerza y de Armas de Fuego por los Funcionarios Encargados de Hacer Cumplir la Ley, considerando los siguientes aspectos: el tamaño de la zona a defender, el grado de protección requerido y el alcance del material. Por lo general, las armas antiaéreas de menor alcance se localizarán en sitios más cercanos para proporcionar protección antiaérea ya sea a puntos estratégicos o al personal militar que ejecuta los patrullajes en el cordón fronterizo, más aún por la gran cantidad de operaciones de control en zonas de frontera que realizan las Fuerzas Armadas y que se evidencian en la Tabla 1 que detallan un total de 17.423 operaciones entre reconocimiento y vigilancia, patrullajes terrestres y operaciones ribereñas.

La ametralladora antiaérea múltiple de calibre 0.50 pulgadas de fabricación americana, sirve para neutralizar objetivos aéreos que vuelan a baja o muy baja altura, su alcance efectivo es hasta 1500 metros de altura y 2000 metros para tiro directo terrestre, es una arma que puede ser auto transportada, auto remolcada y aéreo transportada, característica que le permite ser trasladada a sectores relativamente de difícil acceso (Escuela de Artillería Antiaérea Conjunta, 2008).

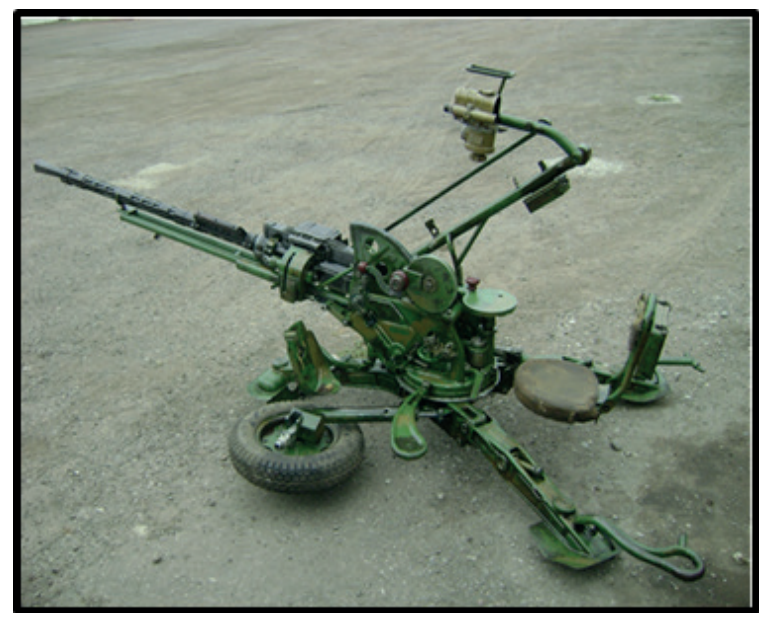

Figura 5. Ametralladora múltiple antiaérea calibre 0.50 pulgadas.

La ametralladora antiaérea ZGU-1P de 14,5 milímetros de fabricación rusa, es una arma de apoyo para batir blancos aéreos, terrestres y navales, dispone de un alcance efectivo de 1500 metros en altura y 2000 metros para tiro directo terrestre, puede ser auto transportada, auto remolcada y aéreo transportada; además por su peso relativamente ligero de $40 \mathrm{~kg}$, puede ser transportada a la espalda del artillero-disparador en distancias cortas, característica que le permite ser trasladada a sectores de muy difícil acceso (Escuela de Artillería Antiaérea Conjunta, 2008).

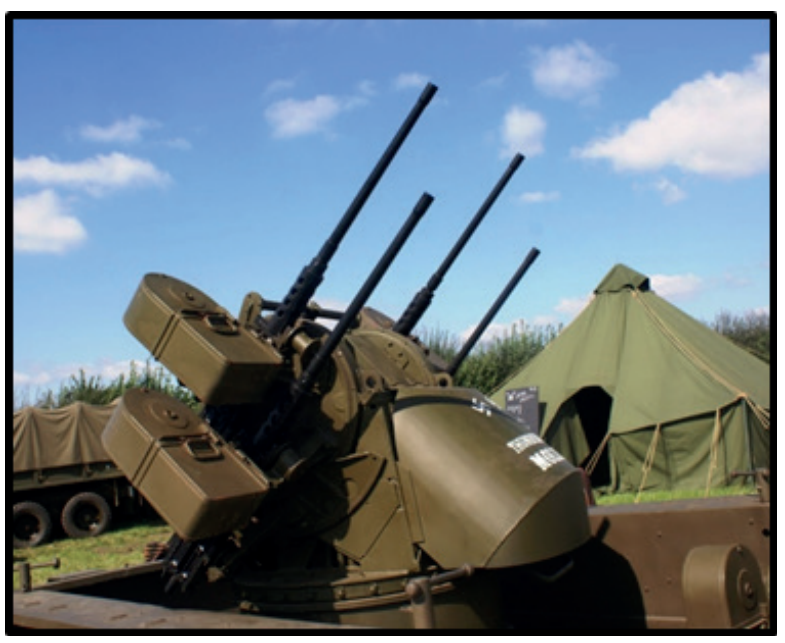

Figura 6. Ametralladora antiaérea ZGU-1P del Ejército

Estos armamentos que forman parte de la artillería antiaérea se convierten en dos aliados para la garantía de los sectores estratégicos cercanos a la frontera norte y del personal, material y equipo que es empleado en este escenario geográfico, generando un ambiente de seguro para el desarrollo de las operaciones militares en el ámbito interno.

\section{Conclusiones}

Las directrices que marcan la seguridad y defensa del Ecuador, deben adaptarse a los continuos cambios, supeditados a factores geopolíticos, legales, militares y el surgimiento de nuevas amenazas en el devenir del tiempo; dicho esto, es fundamental reconocer que las amenazas asimétricas son estructuras que plantean un enfrentamiento no convencional y multimodal a los Estados, y cuyo propósito final es instaurar su "modos operandi" y atentar contras los intereses estratégicos y esenciales de una nación; por tal motivo el Ejército camina a paso firme en la implementación de su proceso de transformación con una visión al 2033, buscando la construcción de nuevos horizontes de progreso y desarrollo, que se enmarcan en una línea irrestricta de la práctica constante de los principios y valores que complementan el profesionalismo de cada uno de sus soldados comprometidos a la consecución de los objetivos institucionales y que buscan un mejor Ecuador, unas excelentes Fuerzas Armadas y un ejército moderno y transformador, catalogado como marca de victoria.

La Fuerza Terrestre, como parte constitutiva de las Fuerzas Armadas del Ecuador, no está utilizando la capacidad antiaérea de forma articulada en las operaciones militares de ámbito interno en la frontera norte, ni en las operaciones de apoyo militar en la lucha contra el narcotráfico, perdiendo las ventajas y beneficios que le puede proporcionar esta capacidad. 
El empleo de los directores de tiro (radares) del Sistema Antiaéreo Oerlikon, se convierte en una herramienta fundamental para cubrir la exploración de ángulos muertos que se generan en la geografía nacional durante la vigilancia de los radares de la Fuerza Aérea Ecuatoriana y pueden integrarse en forma efectiva a la defensa aérea activa para apoyar complementariamente en la vigilancia, detección y evaluación de la amenaza aérea, para su posterior neutralización mediante el acompañamiento de los interceptores aéreos y finalmente su detención por los organismos estatales respectivos, una vez que la aeronave ilícita sea obligada a aterrizar; además, se apuesta al empleo del material de artillería antiaérea en este escenario ante la presencia de grupos ilegales armados colombianos que operan en la frontera norte y que utilizan formas de empleo asimétricas, enfocado únicamente al uso de las ametralladoras antiaéreas que dispone la Fuerza Terrestre, armamento que por sus características no solo puede proporcionar protección antiaérea al personal militar y medios (helicópteros y vehículos blindados) que cumplen operaciones de vigilancia, exploración y reconocimiento terrestre, sino que también pueden proporcionar un adecuado apoyo, debido en gran medida a la gran potencia de fuego que pueden desencadenar contra blancos aéreos, terrestres y fluviales, como garantía y respaldo del sistema de apoyo de fuegos, parte integrante de los sistemas operativos del campo de batalla.

La integración y actualización de la doctrina del sistema de apoyo de fuegos es esencial para cumplir con el empleo de la capacidad antiaérea que dispone la Fuerza Terrestre, concomitante con la implementación de la Doctrina Equinoccio, que permitirá articular los conceptos doctrinarios enfocados a una defensa externa y adecuarlos al apoyo en las operaciones en el ámbito interno, enmarcándose en la normativa legal vigente y en estricto respeto a los tratados y acuerdos internacionales suscritos por el Ecuador.

La naturaleza y empleo del material antiaéreo que dispone el Ejército y de los aviones interceptores que dispone la Fuerza Aérea obligan la búsqueda de un campo de acción multipropósito, que se sustente en la elaboración y la propuesta de una "Ley de Derribo", que permita definir los procedimientos claros para la neutralización y/o destrucción de aeronaves consideradas como hostiles o que ejecuten actividades ilícitas, con la finalidad de contar con un marco legal que permita enfrentar de mejor manera el modo de operación de grupos criminales relacionados al narcotráfico y que utilizan el espacio aéreo ecuatoriano para delinquir.

Finalmente, las Fuerzas Armadas Ecuatorianas, y el Ejército en forma particular, considerando fundamentalmente la realidad económica de nuestro Estado, debe exigir a la autoridad político, en forma respetuosa y subordinada, pero acorde a la normativa legal en vigencia, que en forma paulatina, planificada y por demás organizada, oriente sus esfuerzos para alcanzar al menos unas capacidades mínimas disuasivas de sus Fuerzas Armadas, para alcanzar un aparato militar suficiente, necesario y en condiciones fidedignas de empleo.

\section{Referencias}

Bargent, J. (2019). InSight Crime. https://es.insightcrime. org/noticias/analisis/ecuador-autopista-de-lacocaina-hacia-estados-unidos-y-europa/

Bravo W. y Armas F. (2004). Identificación de las nuevas amenazas de seguridad nacional dentro del contexto interamericano y sus implicaciones en la seguridad y defensa continental. (Tesis de Maestría). Instituto de Altos Estudios Nacionales.

Campaña, M. (13 de Septiembre de 2020). Los delicuentes usan drones para espiar a militares. Diario Expreso, pág. 02.

Comando Conjunto de las Fuerzas Armadas. (2020). Manual Militar de Operaciones de Control de Espacio Aéreo. Departamento de Doctrina Militar Conjunta.

Comando Conjunto de las Fuerzas Armadas. (2020). Manual Militar de Operaciones en el Ámbito Interno. Departamento de Doctrina Militar Conjunta.

Comando de Educación y Doctrina Militar Terrestre. (2020). Manual Fundamental del Ejército: Operaciones. CEDMT.

Comisión técnica de entrega y recepción de los radares. (2020). Informe técnico del proceso de entrega y recepción de los directores de tiro. Quito: 27 B.A.

Delgado, J. M. (2018). El uso de drones comerciales como vectores terroristas. Instituto Español de Estudios Estratégicos, 6-8.

Dirección de Transformación y Desarrollo Militar. (2020). Doctrina Equinoccio. Así Somos, 5.

El Diario. (25 de Abril de 2019). El Diario EC. https:// www.eldiario.ec/noticias-manabi-ecuador/500652a-la-caceria-de-las-narcoavionetas/

El Telégrafo. (20 de Noviembre de 2020). El Ejército lanza la Doctrina Equinoccio y una plataforma de educación en línea.

Escuela de Artillería Antiaérea Conjunta, “. O. (2008). Conocimiento de la ametralladora múltiple 0.50 pulgadas y Conocimiento de la pieza antiaérea $Z G U-1 P$. Fuerza Aérea Ecuatoriana.

Fuerza Aérea Ecuatoriana. (2013). Manual de Instrucción de Defensa Aérea. Comando de educación y doctrina de la Fuerza Aérea.

Fuerza Terrestre. (2020). Manual Fundamental Apoyo a las Instituciones del Estado. Comando de Educación y Doctrina Militar Terrestre.

La Voz. (20 de Enero de 2016). La Voz. Los siete países de Latinoamérica que permiten el derribo de aviones: https://www.lavoz.com.ar/politica/ los-siete-paises-de-latinoamerica-que-permiten-elderribo-de-aviones 
Larraín, \& Horacio. (2015). Las amenazas asimétricas como una modalidad de resolución de conflictos. Revista Política y Estratégia N 99., 105.

Lohmuller, M. (23 de Abril de 2014). InSight Crime. Obtenido de Bolivia: El más reciente país en Latinoamérica que aprueba ley para derribar avionetas con droga. https://es.insightcrime.org/ noticias/noticias-del-dia/bolivia-el-nuevo-pais-delatinoamerica-en-haber-aprobado-ley-para-derribaravionetas-con-droga/

Mayor Davis, J. (2013). Cómo derrotar las futuras amenazas híbridas. Military Review, 13.

Ministerio de Defensa Nacional. (2014). Agenda Política de la Defensa 2014-2017. Midena.

Ministerio de Defensa Nacional. (2018). Política Nacional de Defensa del Ecuador 2018. Ministerio de Defensa Naciona.

Ministerio de Defensa Nacional. (2020). Rendición de cuentas 2019. MIDENA.

Ortiz, S. (2021). El Comercio EC. https://www. elcomercio.com/actualidad/record-incautaciondrogas-ecuador-2020.html

Pastrana, E., \& Trujillo, L. (2011). La Operación Fénix de las Fuerzas Armadas Colombianas a la luz del Derecho Internacional. Colombia.

Plan V. (25 de Junio de 2020). Plan V: Hacemos periodismo. https:/www.planv.com.ec/historias/ sociedad/se-descubre-pista-clandestina-2kilometros-la-mas-grande-del-ecuador

RCN Noticias. (2020). Noticiasrcn.com. https:/www. noticiasrcn.com/nacional/colombia-sigue-siendoel-mayor-pais-productor-de-coca-en-el-mundoonu-359013

Tcrn. Montenegro, R. (2019). La Defensa Aérea y su importancia en la Seguridad Nacional. Revista de la Fuerza Aérea Ecuatoriana, 37. 